\title{
Mini-Review
}

Editor's Note: Two reviews in this week's issue examine the rapidly expanding interest in autism research in the neuroscience community. Moldin et al. provide a brief prospective on the overall state of research in autism. DiCicco-Bloom and colleagues summarize their presentations at the Neurobiology of Disease workshop at the 2005 Annual Meeting of the Society for Neuroscience.

\section{The Developmental Neurobiology of Autism Spectrum Disorder}

\author{
Emanuel DiCicco-Bloom, ${ }^{1}$ Catherine Lord, ${ }^{2}$ Lonnie Zwaigenbaum, ${ }^{3}$ Eric Courchesne, ${ }^{4,5}$ Stephen R. Dager, ${ }^{6}$ \\ Christoph Schmitz, ${ }^{7}$ Robert T. Schultz, ${ }^{8}$ Jacqueline Crawley, ${ }^{9}$ and Larry J. Young ${ }^{10}$ \\ ${ }^{1}$ Departments of Neuroscience and Cell Biology and Pediatrics (Neurology), Robert Wood Johnson Medical School, University of Medicine and Dentistry of \\ New Jersey, Piscataway, New Jersey 08854, ${ }^{2}$ University of Michigan Autism and Communication Disorders Center, Departments of Psychology and \\ Psychiatry, University of Michigan, Ann Arbor, MI 48109-2054, ${ }^{3}$ Department of Pediatrics, McMaster University, Hamilton, Ontario, L8N 3Z5, Canada, \\ ${ }^{4}$ Department of Neurosciences, University of California, San Diego, La Jolla, California 92093, ${ }^{5}$ Center for Autism Research, Children's Hospital Research \\ Center, San Diego, California 92123, ${ }^{6}$ Departments of Radiology, Psychiatry, and Bioengineering, University of Washington School of Medicine, Seattle, \\ Washington 98105, ${ }^{7}$ Department of Psychiatry and Neuropsychology, Division of Cellular Neuroscience, Maastricht University, 6200 MD Maastricht, The \\ Netherlands, ${ }^{8}$ Yale Child Study Center and Diagnostic Radiology, Yale University, New Haven, Connecticut 06520, ${ }^{9}$ Laboratory of Behavioral Neuroscience, \\ Intramural Research Program, National Institute of Mental Health, Bethesda, Maryland 20892-3730, and ${ }^{10}$ Center for Behavioral Neuroscience and \\ Department of Psychiatry, Yerkes National Primate Research Center, Emory University School of Medicine, Atlanta, Georgia 30329
}

Key words: cerebellum; autism; behavior; cognitive; brain development; imaging; mice; fMRI; genetics; Purkinje neurons; human forebrain development; cerebral cortex

The autism spectrum disorder (ASD) is among the most devastating disorders of childhood in terms of prevalence, morbidity, outcome, impact on the family, and cost to society. According to recent epidemiological data, $\sim 1$ child in 166 is affected with ASD, a considerable increase compared with estimates compiled 15-20 years ago (Fombonne, 2003a,b). Although at one time considered an emotional disturbance resulting from early attachment experiences (Bettelheim, 1967), ASD is now recognized as a disorder of prenatal and postnatal brain development. Although ASD is primarily a genetic disorder involving multiple genes, insights into underlying mechanisms will require a multidisciplinary approach. Assessment of the earliest clinical signs and symptoms and the functional and structural networks by neuroimaging and neuropathology can be used to identify the underlying brain regions, neural networks, and cellular systems. In turn, the efforts of human and animal geneticists and neuroscientists are needed

\footnotetext{
Received April 20, 2006; revised May 18, 2006; accepted May 18, 2006.

This work was supported by National Institutes of Health Grants NS32401 and HD23315 (E.D.-B.), the National Alliance for Autism Research (www.autismspeaks.org), and the New Jersey Governor's Council on Autism. This course would not have been possible without the tireless efforts of Dr. Colleen D. McNerney, Director of Educational Programs, Society for Neuroscience. We thank Dr. James H. Millonig for insightful critical review and Dr. Gary Westbrook for editorial support.

Authors are listed in the order of course appearance.

Correspondence should be addressed to Emanuel DiCicco-Bloom, Department of Neuroscience and Cell Biology, Robert Wood Johnson Medical School, 675 Hoes Lane, RWJSPH Room 362, Piscataway, NJ 08854. E-mail: diciccem@umdnj.edu.

D0I:10.1523/JNEUROSCI.1712-06.2006

Copyright $\odot 2006$ Society for Neuroscience $\quad 0270-6474 / 06 / 266897-10 \$ 15.00 / 0$
}

to define molecular and protein signaling pathways that mediate normal as well as abnormal development of language, social interaction, and cognitive and motor routines. In this review, we focus on several issues: the earliest manifestations of ASD, reported abnormalities of brain growth, functional neural networks, and neuropathology. We also consider the possible etiological factors and the challenges of creating animal models for this uniquely human behavioral disorder.

Autism spectrum disorder: phenotypes and clinical diagnosis ASD comprises several different disorders as defined by deficits in social behaviors and interactions. These deficits prevent the development of normal interpersonal relationships of affected patients with their parents, siblings, and other children. Deficits in nonverbal communication include reduced eye contact, facial expression, and body gestures (American Psychiatric Association, 1994). These disorders include prototypic autistic disorder, Asperger syndrome, and pervasive developmental disorder-not otherwise specified (PDD-NOS). Autistic disorder has three core symptom domains: deficits in communication, abnormal social interactions, and restrictive and/or repetitive interests and behaviors. Autistic disorder is typically noticed in the first or second year of life. The manifestations include delay or abnormality in language and play, repetitive behaviors, such as spinning things or lining up small objects, or unusual interests such as preoccupations with stop signs or ceiling fans. Asperger syndrome also involves social symptoms but language development and non- 
verbal intelligence are nearly normal. Asperger syndrome, however, may not be apparent until a child is older. PDD-NOS (atypical autism) differs from autistic disorder by the absence of repetitive behaviors or communication deficits or the presence of subtle deficits in all three core symptom domains. In the past, more than half of children with autistic disorder had nonverbal skills in the range of mental retardation (MR) despite the fact that their nonverbal skills typically exceeded their verbal performance. However, recent epidemiological studies suggest that this may no longer be the case, perhaps because of better identification of mild cases, the effects of earlier and more effective special education interventions, and/or more accurate assessment of nonverbal intelligence in children with limited social motivation (Chakrabarti and Fombonne, 2001). Because these three disorders frequently occur within the same family, they may not be genetically distinct (Lord and Bailey, 2002).

There is marked phenotypic diversity in ASD, with impairment in each symptom domain varying greatly between individuals. In addition, there may be several distinct phenotypic profiles. For example, social development and repetitive behaviors follow different timelines, with social deficits often improving during preschool years, whereas repetitive behaviors become more obvious. Approximately $25-35 \%$ of children develop a few spontaneous words and early social routines (e.g., playing peeka-boo) at $\sim 1$ year of age, reach a plateau for several months, and then gradually lose the skills altogether. Those with this regression may regain the skills months later [or sometimes not at all (Luyster et al., 2005)]. Another 25\% of children develop seizures during adolescence.

The diagnosis of ASD can now be made in children as young as 2 years, as well as adults using a combination of standardized instruments: a parent interview (e.g., the Autism Diagnostic Interview-Revised) and an observational scale (e.g., the Autism Diagnostic Observation Schedule). These instruments are currently the most reliable, sensitive, and specific tools for research. Although these instruments are now being used as metrics for ASD severity, caution is required because specific group norms have not been defined for different age groups or distinct intellectual and verbal levels (Lord et al., 2001). ASD is not commonly identified before 2 years of age. The earliest signs recognized in infancy ( $\leq 1$ year) or toddlers are nonspecific (e.g., irritability, passivity, difficulties with sleeping and eating), followed by delays in language, including babbling and response to speech, and in social engagement. By 3 years of age, difficulties in the three major domains (social reciprocity, communication, and restricted/ repetitive interests) are typically observed. ASD is easiest to differentiate from other disorders, such as attention deficit disorder and language impairments, in late preschool and early school years. Thereafter, the consequences of compensatory strategies and mental retardation make distinctions among disorders more difficult.

Because early developmental interventions may significantly alter ASD outcomes, diagnostic instruments that are effective before 2 years of age are a priority. Toward this goal, investigators are focusing on the early behavioral signs that previously were identified only from retrospective reports by parents and analysis of home videotapes (Zwaigenbaum et al., 2006). In some studies, as many as $50 \%$ of parents recall abnormalities during the first year, including extremes of temperament and behavior (from marked irritability to alarming passivity), poor eye contact, and lack of response to parental voices or interaction. Home videos reveal similar developmental differences by 12 months of age. However, such retrospective reporting may lead to restricted and possibly biased sampling and leave uncertainty about the onset and progression of early signs. To address these limitations, investigators have turned to prospective studies of infants at high risk for ASD. Siblings born to families with an ASD child have a 50- to 100-fold greater chance of ASD, with a recurrence rate of 5-8\% (Szatmari et al., 1998). These longitudinal studies offer several methodological advantages, including the use of standardized conditions with a priori selection of time points and measures based on specific hypotheses (Zwaigenbaum et al., 2006). Prospective data indicate that at 12 months of age, atypical behaviors can distinguish siblings later diagnosed with ASD from other siblings and low-risk control infants. These behaviors cross several functional domains, including visual attention (tracking), imitation, social responses (orienting to name, anticipatory responses, eye contact, reciprocal smiling), motor control, and reactivity (Zwaigenbaum et al., 2005). There is also evidence of atypical language trajectories, with mild delays at 12 months progressing to more severe delays by 24 months (Zwaigenbaum et al., 2005; Landa and Garrett-Mayer, 2006). Yirmiya et al. (2006) also reported that 4-month-old ASD siblings show decreased synchrony during infant-led interactions with their mothers, suggesting that subtle social abnormalities may precede more obvious late impairments. These early deficits in social, communicative, and cognitive functions are a starting point to look for evidence of abnormal brain growth, development, and function by clinical imaging and neuropathological studies.

\section{The neurobiology of ASD}

Studies of the ASD brain using structural and functional imaging and neuropathological techniques have revealed macroscopic and microscopic abnormalities of development.

\section{Morphometric and chemical neuroimaging studies}

During early childhood, brain volume in ASD shows abnormal enlargement, but these differences diminish somewhat by later childhood or adolescence. This pattern has been detected only recently because for much of its 70 year history, ASD brain abnormalities were viewed as static. Thus, the possibility of agedependent growth abnormalities was not appreciated (Courchesne, 2004). Most anatomical studies of ASD focused on the older child, adolescent, or adult (Cody et al., 2002), rarely investigating the young, developing brain (Courchesne et al., 2001, 2004; Sparks et al., 2002; Hazlett et al., 2005). The few cross-sectional studies that examined age-related changes reveal a complex pattern of growth abnormalities in the cerebellum, cerebrum, and amygdala and possible differences in hippocampus (Hashimoto et al., 1995; Courchesne et al., 2001; Aylward et al., 2002; Carper et al., 2002; Sparks et al., 2002; Herbert et al., 2004; Schumann et al., 2004; Carper and Courchesne, 2005; Hazlett et al., 2005). Age-related differences in specific brain region growth were also apparent in a meta-analysis (Redcay and Courchesne, 2005).

Brain size has been defined using head circumference, a reliable indicator of volume especially during early childhood; volumetric calculations using magnetic resonance imaging (MRI); and postmortem brain weights. At birth, the average head circumference in ASD patients is approximately normal (Courchesne and Pierce, 2005a). However, by 3-4 years of age, brain size in ASD exceeds normal average by $\sim 10 \%$ based on in vivo MRI studies and a meta-analysis of postmortem brain weight and MRI morphometry (Courchesne et al., 2001; Sparks et al., 2002; Redcay and Courchesne, 2005). A recent brain volume study using a larger toddler sample (51 children; 18-35 months 
of age) observed a somewhat smaller $\sim 5 \%$ increase (Hazlett et al., 2005). By 6-7 years of age, brain size in ASD may exhibit only a small increase (Courchesne et al., 2001; Sparks et al., 2002; Redcay and Courchesne, 2005; Carper et al., 2006). However, forthcoming data from the largest study reveals a persistent $\sim 5 \%$ difference at older ages (Schultz et al., 2005a), consistent with extensive head circumference data in older patients. Thus, all emerging data indicate that there is a brain growth phenotype in ASD. At the tissue level, brain enlargement reflects both increased cerebral gray and white matter (Courchesne et al., 2001; Carper et al., 2002; Hazlett et al., 2005), especially white matter immediately underlying the cortex (Herbert et al., 2004). There is also increased cerebellar white and gray matter (Courchesne et al., 2001), although this finding may vary with sample selection and methodology (Hazlett et al., 2005). In contrast, the cerebellar vermis, which is predominantly gray matter, is reduced in size (Hashimoto et al., 1995; Courchesne et al., 2001; Kaufmann et al., 2003).

Magnetic resonance spectroscopy (MRS) can be used to detect regional concentrations of neuron-related molecules such as $\mathrm{N}$-acetyl aspartate, creatine, and myoinositol. Given the brain enlargement in ASD, one might have predicted increases in neuronal markers attributable to enhanced neuronal or synaptic density. However, these markers were all decreased in 3- to 4 -year-old children with ASD (Friedman et al., 2003). The combination of altered molecular markers and an increase in white and gray matter could reflect changes in (1) the numbers and sizes of neurons and glia; (2) the elaboration of axons, dendrites and synapses; (3) axodendritic pruning; (4) programmed cell death; (5) production of cortical columns; or (6) myelination. An inflammatory response has also been described in frontal cortex and cerebellar regions, including cytokine production and activation of microglia and astrocytes (Courchesne and Pierce, 2005b; Vargas et al., 2005).

\section{Neuropathological studies}

Postmortem studies can directly characterize brain abnormalities in ASD. Classical studies have focused primarily on autistic disorder. These studies were limited by small sample sizes (often just case reports), use of possibly biased quantification methods, and the presence of comorbid mental retardation and/or epilepsy (Palmen et al., 2004). Nevertheless, these studies revealed abnormalities in brain development. Approximately $20 \%$ of the cases exhibit macrocephaly (head circumference $>97$ th percentile), a finding already noted in some children in the first report on autistic disorder (Kanner, 1943). Microscopically, the following consistent findings have been identified: decreased numbers of cerebellar Purkinje cells [ 21 of 29 cases in 8 studies, 22 of 24 with MR and 11 of 24 with epilepsy (Williams et al., 1980; Ritvo et al., 1986; Fehlow et al., 1993; Kemper and Bauman, 1993; Guerin et al., 1996; Bailey et al., 1998; Fatemi et al., 2002; Lee et al., 2002)], age-related changes in cerebellar nuclei and inferior olive [5 of 5 cases in 1 study, 5 of 5 with MR and 4 of 5 with epilepsy (Bauman, 1991)], brainstem and olivary dysplasia [4 of 6 cases in 2 studies, all with MR and 4 of 6 with epilepsy (Rodier et al., 1996; Bailey et al., 1998)], alterations in the neocortex, such as misoriented pyramidal neurons [ 6 of 15 cases in 5 studies, 14 of 15 with MR and 8 of 15 with epilepsy (Coleman et al., 1985; Hof et al., 1991; Kemper and Bauman, 1993; Guerin et al., 1996; Bailey et al., 1998)], signs of cortical dysgenesis [ 30 of 32 cases in 6 studies, 16 of 22 with MR and 8 of 15 with epilepsy (Bailey et al., 1998; Fatemi, 2001; Fatemi and Halt, 2001; Casanova et al., 2002a,b; Araghi-Niknam and Fatemi, 2003)], and increased cell packing density and smaller neurons in the limbic system [ 9 of 15 cases in 4 studies, 14 of 15 with MR and 8 of 15 with epilepsy (Kemper and Bauman, 1993; Guerin et al., 1996; Raymond et al., 1996)]. The most consistent abnormalities reported by multiple investigators are decreased cerebellar Purkinje neurons and cerebral cortex dysgenesis. Data on the limbic system and age-related hindbrain changes lack independent laboratory replication. These findings may represent alterations in primary developmental processes such as precursor proliferation, programmed cell death, neuron migration, axodendritic outgrowth, synaptogenesis, and pruning, although the pathological consequences of epilepsy and its treatment must also be considered.

By themselves the microscopic changes do not explain macrocephaly nor evidence of an enlarged brain in neuroimaging studies (Cody et al., 2002; Palmen and van Engeland, 2004; Courchesne and Pierce, 2005a). However, few postmortem studies included brains from the first years of life when the agedependent enlargement has been most clearly characterized (Courchesne et al., 2001; Sparks et al., 2002; Hazlett et al., 2005; Redcay and Courchesne, 2005). In contrast, preliminary evidence using state-of-the-art stereological methods suggests a $>10 \%$ increase in mean cortical neuronal density as well as cortical neuron number in six subjects with ASD $(12.3 \pm 3.4$ years of age; mean age \pm SEM; MR, 6 of 6 ; epilepsy, 3 of 6$)$ compared with six age-matched controls (12.8 \pm 3.8 years of age) (C. Schmitz, unpublished observations). ASD subjects also exhibit an $\sim 5 \%$ reduction in minicolumn width in cortical areas M1, V1, and frontal association cortex [areas 4, 17, and 9 of Brodmann (1909)] and S1 [area 3b of Vogt and Vogt (1919)] (C. Schmitz and M. Casanova, unpublished observations). The latter results support previous findings of changes in minicolumnar organization in other cortical regions in ASD (Casanova et al., 2002a). A reduction in minicolumn width could reflect changes in GABAergic systems (Blatt et al., 2001; Schmitz et al., 2005) that may alter lateral inhibition (Gustafsson, 1997; Bertone et al., 2005) or underlie excess local cerebral connectivity at the expense of longdistance connectivity (Courchesne and Pierce, 2005b). Other studies raise the possibility of changes in synaptic density and the composition of nicotinic receptors (Lee et al., 2002; Martin-Ruiz et al., 2004; Mukaetova-Ladinska et al., 2004).

\section{Functional neuroimaging studies}

Because the diagnosis of ASD is based on select behavioral disturbances that normally map onto specific brain networks, functional MRI (fMRI) can be useful to examine the neural systems affected in ASD. The three core symptom domains likely involve widely dispersed neural systems, perhaps implying a generalized cellular abnormality. In contrast, some abilities such as basic perceptual skills and overall intelligence are often spared, suggesting that not all brain systems are equally affected. Although ASD alters language, attention, communication, and social interactions, only the latter has received significant attention using fMRI (Schultz and Robins, 2005). The earliest fMRI work focused on social perception, such as person recognition through the face (Schultz et al., 2000). More recent work has examined the perception of facial expression, joint attention, empathy, and social cognition (Fig. 1). These studies indicate that the skill deficits of ASD are accompanied by reduced neural activity in regions that normally govern the specific functional domain. For example, deficits in joint attention are associated with reduced activity in the posterior superior temporal sulcus (Pelphrey et al., 2005), whereas deficits in social perception and/or emotional engagement and arousal are associated with reduced activity in the 


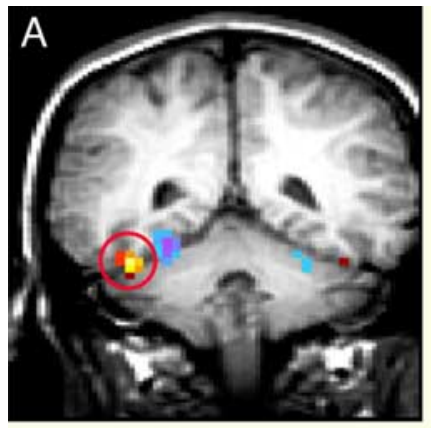

Control

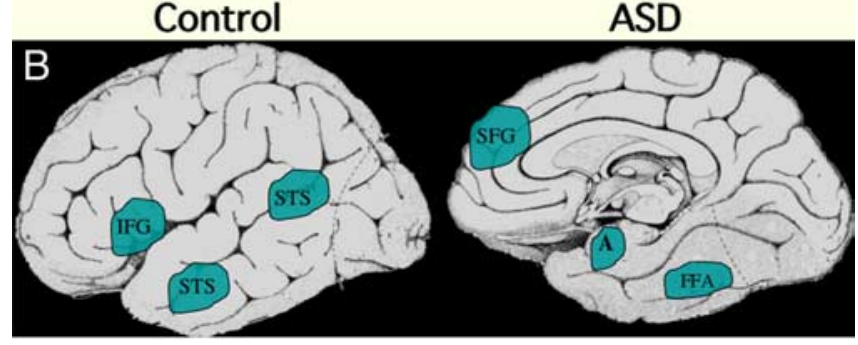

Lateral

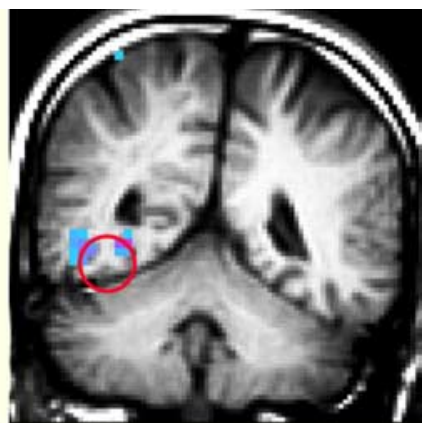

ASD

Medial
Figure 1. Functional MRI abnormalities observed in ASD. $\boldsymbol{A}$, These coronal MRI images show the cerebral hemispheres above, the cerebellum below, and a circle over the fusiform gyrus of the temporal lobe. The examples illustrate the frequent finding of hypoactivation of the fusiform gyrus to faces in an adolescent male with ASD (right) compared with an age- and IQmatched healthy control male (left). The red/yellow signal shows brain areas that are significantly more active during perception of faces; signals in blue show areas more active during perception of nonface objects. Note the lack of face activation in the boy with ASD but average levels of nonface object activation. $\boldsymbol{B}$, Schematic diagrams of the brain from lateral and medial orientations illustrating the broader array of brain areas found to be hypoactive in ASD during a variety of cognitive and perceptual tasks that are explicitly social in nature. Some evidence suggests that these areas are linked to form a "social brain" network. IFG, Inferior frontal gyrus (hypoactive during facial expression imitation); pSTS, posterior superior temporal sulcus (hypoactive during perception of facial expressions and eye gaze tasks); SFG, superior frontal gyrus (hypoactive during theory of mind tasks, i.e., when taking another person's perspective); A, amygdala (hypoactive during a variety of social tasks); FG, fusiform gyrus, also known as the fusiform face area (hypoactive during perception of personal identity) (Schultz, 2005; Schultz and Robins, 2005).

amygdala (Baron-Cohen et al., 1999; Critchley et al., 2000; Pierce et al., 2001). Some exciting new work suggests that "mirror" neurons (i.e., motor neurons that fire when the animal or person watches the actions of others) might be involved in deficits in empathy (Dapretto et al., 2006), whereas positron emission tomography studies showed medial prefrontal and amygdaloid area deficits during theory of mind tasks (i.e., when taking someone else's perspective) (Castelli et al., 2002).

Although the deficits in ASD are undoubtedly widely distributed, the best replicated $\mathrm{AMRI}$ abnormality is hypoactivation of the fusiform face area (FFA) (Schultz, 2005). Individuals with ASD have difficulties with face perception (Langdell, 1978; Klin et al., 2002). Although nearly all fMRI studies report FFA hypoactivation, its meaning depends greatly on the psychological task and the correlation with other behavioral measures. In normal subjects, tasks that require the participant to individuate specific faces show much more FFA activation than tasks that only require basic level "person detection." The latter task might be engaged by passive viewing (Grill-Spector et al., 2004). Because individuals with ASD do not have deficits in detecting people versus other objects, it is not unexpected that there are smaller group differences with passive viewing of faces. It will be important that future studies use fMRI tasks that drive the social brain systems in ways that mimic the everyday ASD-associated deficits. In addition, collection of behavioral data along with fMRI should help clarify factors contributing to regional activation abnormalities. For example, Dalton et al. (2005) found that individual differences in FFA hypoactivation correlated inversely with the time the participant spent fixating visually on the subject's eye region. Other recent studies indicate that the degree of neural activation can predict individual differences in functional performance in ASD subjects (Pelphrey et al., 2005; Schultz et al., 2005b; Dapretto et al., 2006). Thus, measuring parameters such as eye tracking or autonomic function, a marker of emotional arousal and responsiveness, may identify unique patterns of neural activation. Last, the improving quality of imaging data now allows statistical modeling of brain networks that seem to be involved in social cognition and social perception, allowing one to construct dynamic models of the way different nodes in different brain areas work together to achieve functional behaviors. It is now possible to model the temporal sequence of specific node activation during prolonged behavioral tasks that may provide insight into the manner by which brain regions contribute to larger functional networks in normal subjects compared with ASD (Just et al., 2004; Schultz et al., 2005b). In turn, these distributed patterns of neural activity can be correlated with specific genetic alleles, thereby linking the pathway from gene to brain to behavior. In this regard, neuroimaging studies could form the glue that binds genetics to behavior.

\section{The etiology of ASD}

The foregoing evidence indicates that ASD involves changes in regional brain anatomy and functional neural networks and likely results from abnormal regulation of multiple ontogenetic processes. What underlies the abnormal brain development? Studies of human populations indicate that ASD is primarily a heritable disorder. We cannot exclude of course the possibility that other factors also contribute to the manifestations of the disorder. In families with an ASD child, the risk of the disorder in the next sibling is 50 times greater than in the general population. ASD concordance rates in monozygotic and dizygotic twins indicate that heritability is $>90 \%$. Studies modeling ASD transmission suggest that it is polygenic, involving 3-15 alleles per individual with complex gene-gene and/or gene-environment effects (Risch et al., 1999; Szatmari, 1999). Genome-wide linkage scans have been used to map the location of susceptibility genes. At least 12 genome scans have been completed, which have varied with respect to genotyping methods (i.e., markers used, map density), phenotypic methods (e.g., diagnostic instruments), and statistical methods. Although few findings reach the Lander and Kruglyak (1995) criteria for statistical significance, there is convergence of suggestive linkages on chromosomes $2 \mathrm{q}, 7 \mathrm{q}$, and $16 \mathrm{p}$ (Wassink et al., 2004; Xu et al., 2004). Over 100 candidate genes have been studied (Wassink et al., 2004), but few findings have been replicated. Very recently, however, association of the cerebellar developmental patterning gene ENGRAILED 2 with ASD has been reported (Gharani et al., 2004) and replicated in three separate populations (Fig. 2) (Benayed et al., 2005). As the first genetic allele to be reproducibly associated with ASD, it may contribute disease susceptibility in as many as $40 \%$ of cases. There are other promising candidate genes, including the UBE3A locus (the gene for Angelman's syndrome), several GABA system genes on chromosome 15q11-13, and the serotonin transporter gene on chromosome 17q (Devlin et al., 2005). Analysis of ASD cases with specific chromosomal abnormalities has also helped identify genomic regions that may harbor susceptibility genes (Vorstman 


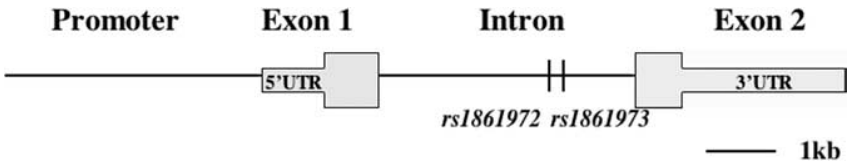

Figure 2. Genomic structure and association results of the ENGRAILED 2 gene. EN2 is encoded by two exons separated by a single intron in $8.1 \mathrm{~kb}$. Eighteen polymorphisms within EN2 have been tested for association with ASD, and two intronic SNPs (rs1861972 and rs 1861973) have consistently displayed significant results. Rs 1861972 is an A/G polymorphism, and rs 1861973 is a C/T polymorphism. Significant association for the A allele of rs 1861972 and the C allele of rs 1861973, both individually and as a haplotype, has been observed in three separate datasets, providing genetic evidence that EN2 is likely to be an ASD susceptibility locus (Gharani et al., 2004; Benayed et al., 2005) [ASD (Mendelian Inheritance in Man MIM 608636); EN2 (MIM 131310)].

et al., 2006; Xu et al., 2004). Investigators are now collaborating to pool samples and thus maximize statistical power. The examination of specific ASD-related phenotypes (endophenotypes, e.g., language impairment) may be more informative genetically than the categorical diagnosis of ASD (Bradford et al., 2001; Alarcon et al., 2005).

There has also been considerable attention to the possible contribution of environmental factors (London, 2000). Several prenatal exposures have been associated empirically with ASD including thalidomide, certain viral infections, and maternal anticonvulsants, especially valproic acid (Trottier et al., 1999; Arndt et al., 2005). Although these factors independently account for few cases, environmental factors may interact with genetic susceptibility to increase the likelihood of ASD. For example, some data implicate a possible role of immune factors, including an increased family history of autoimmune diseases and presence of autoantibodies to neural antigens (Ashwood and Van de Water, 2004; Connolly et al., 2006).

\section{Is it possible to create an animal model of ASD?}

\section{Rationales for model development}

Given the multifactorial etiology and the tremendous phenotypic diversity within each core symptom domain, it is not surprising that there is no single animal model that captures all of the molecular, cellular, or organismic features of ASD. Challenged by this complexity, one useful approach has been to focus on single features to study the underlying mechanisms (DiCicco-Bloom, 2005). Based on the available neuroimaging, genetic, and pathological evidence of a developmental origin, animal studies have followed four general approaches or rationales, which may be categorized as fundamental neurobiology, endophenotypic, genetic, and pathogenetic.

The fundamental neurobiology approach posits that basic mechanisms are conserved among organisms and are expanded on or modified through evolution. By defining molecular and cellular mechanisms that regulate brain region development or mediate cognitive functions, we can identify molecular targets whose disruption may contribute to an ASD-related abnormality. For example, research on oxytocin/vasopressin indicates that these neuropeptides participate in social recognition, affiliation, and maternal-infant bonding across many species. Consequently, genetic findings in the animal model are now being applied to studies of social deficits in human ASD populations (Lim et al., 2005). Language learning in the songbird is another interesting model, in which auditory input, song imitation, and FoxP1/2 gene expression demonstrate parallels to human language (Teramitsu et al., 2004). Finally, growth factor regulation of neurogenesis in ASD-affected regions including the cerebral cortex, hippocampus, and cerebellum indicate that proliferation is controlled by a balance of promitogenic [bFGF (basic fibroblast growth factor), IGF1 (insulin-like growth factor), SHH (sonic hedgehog) (Vaccarino et al., 1999; Wechsler-Reya and Scott, 1999; Cheng et al., 2001, 2002; Li and DiCicco-Bloom, 2004)] and antimitogenic [PACAP (pituitary adenylate cyclase-activating polypeptide) (Suh et al., 2001; Carey et al., 2002; Nicot et al., 2002)] signals. Acting via cognate receptors, growth factors elicit rapid changes in select cell cycle regulators that determine progress from G1 into $S$ phase. Thus, one may propose that brain enlargement could follow changes in the activity of promitogenic and antimitogenic signals from ligand to receptor to cell cycle regulator, all potential candidate genes.

The endophenotype approach investigates mechanisms underlying defined traits that are not necessarily confined to a specific diagnostic category such as ASD, specific language impairment, or attention disorders. ASD-related endophenotypes include social isolation, changes in neurotransmitter systems, or deficits of Purkinje neurons. Using newborn and adult nonhuman primates, such studies have examined roles of the hippocampus and amygdala in social function. These studies initially used destructive or chemical lesions, but more recent studies have used modifications of newborn rearing conditions (Winslow, 2005). Many mouse mutants show Purkinje cell deficits, although Engrailed 2 (En2) has been of particular interest for several reasons. Specifically, En2 deletion or overexpression produces Purkinje cell deficits; the diminished posterior cerebellar vermis and lobules in mice are also seen in some human autism neuropathology, and human EN2 localizes close to the chromosomal 7 region identified by several ASD genome linkage scans. Studies of En2 gene overexpression (Baader et al., 1998; Benayed et al., 2005) as well as gene deletion have been performed in vivo and in vitro (Millen et al., 1994; Rossman et al., 2005). Overexpression of En2 in neural precursors in culture maintains precursor proliferation and reduces neuronal differentiation, mechanisms that could conceivably contribute to ASD cerebellar neuropathology.

The genetic approach uses targeted mutations in mice to define mechanisms regulated by genes considered important for ASD. The genes tested are known to cause ASD, are associated with ASD, or have been proposed as candidate genes based on their developmental functions or localization to chromosomal regions identified by linkage analyses. A well characterized ASDcausing genetic disorder, tuberous sclerosis (20-40\% have ASD), results from mutations in either of two genes, hamartin and tuberin, that function as tumor suppressors and interact with protein translational machinery. Other Mendelian genetic disorders manifesting aspects of ASD include fragile X mental retardation, Rett's, Prader-Willi, Angelman, and Smith-Lemli-Opitz syndromes (Polleux and Lauder, 2004; Xu et al., 2004). The related mouse mutants are under active investigation. One may speculate that less severe alleles at these loci could contribute to ASD susceptibility in the absence of the primary clinical condition. Regarding disease-associated genes, EN2 exhibits replication of a specific genetic allele with ASD (Benayed et al., 2005). However, for several genes, there is repeated association but not for the same single nucleotide polymorphism (SNP). Should these different SNPs produce similarly altered gene function, one may consider the possibility that different disease alleles may equally disrupt gene function to contribute to disease susceptibility (Wassink et al., 2004). This has been suggested for genes involved in neurotransmitter systems (serotonin transporter). However, final conclusions about the contributions to ASD susceptibility must await genetic replication in separate affected populations 
(Bartlett et al., 2005). In some cases, gene defects apparently cause ASD in a restricted manner: in two families, mutations in synaptic adhesion molecules (neuroligin 3 and 4) account for ASD. Consequently, expression of mutant neuroligins in cells and animals is being used to examine the roles of synaptodendritic defects in cognitive disorders like ASD.

The pathogenetic approach examines the effects of known or hypothesized developmental insults such as teratogens, maternal infections, and hindbrain congenital syndromes. The observation that 4 of 15 human embryos exposed on gestational days 20-24 to the teratogenic antinausea drug thalidomide displayed ASD led to the proposal that insults to the hindbrain, at the time that the neural tube is closing and craniocerebellar neurons are being generated, may contribute to ASD (Strömland et al., 1994; Arndt et al., 2005). Signs of ASD are observed in several congenital hindbrain syndromes including CHARGE, Goldenhar, and Mobius (Miller et al., 2005). Rodier et al. (1996) mimicked this teratogenic stimulus by exposing embryonic day 12 pregnant rats to valproic acid, a common anticonvulsant associated with ASD and cognitive deficits. These animals developed cranial and Purkinje neuron deficits and behavioral abnormalities in eye-blink conditioning as observed in ASD (Arndt et al., 2005). ASD has also been associated with gestational rubella and possibly influenza. Adult offspring of pregnant mice that sustain human influenza-induced pneumonia exhibit abnormalities in behavior as well as in molecular markers for neurons, glia, and inflammation. Because infectious particles are not present in the brain, this suggests that circulating maternal cytokines could be primary mediators of pathogenesis (Shi et al., 2005), an intriguing result given MHC (major histocompatibility complex) class I expression and function in axonal pathfinding and synaptogenesis (Boulanger and Shatz, 2004).

\section{Mouse behavioral models of ASD}

An ideal mouse model of ASD should display behavioral symptoms with face validity for the defining symptoms of (1) reciprocal social interactions, (2) social communication, and (3) stereotyped, ritualistic, and repetitive behaviors and/or narrow restricted interests. Tasks that could examine these behavioral symptoms in mice are being developed (Young et al., 2002; Crawley, 2004). Of course, behavioral features will need to conform to species-relevant tasks, and certain limitations may be expected.

Tasks of social approach measure the propensity of mice to spend time with another animal rather than nonsocial novel objects. These tasks measure detailed components of the social interaction. An automated three-chambered apparatus in which all social approach is initiated by the subject mouse has been fully characterized (Fig. 3) (Moy et al., 2004; Nadler et al., 2004). In addition, single-chamber and multichamber arenas that use standard video-tracking and observer event-recording methods have been used widely to quantify social interaction, social recognition, and social memory (Insel and Young, 2001; Winslow and Insel, 2002; Bolivar and Flaherty, 2003; Brodkin et al., 2004). The second symptom, social communication, may be measured most effectively in mice using olfactory and auditory communication tasks (Winslow and Insel, 2002; Wrenn et al., 2003; Blanchard et al., 2003; Petrulis et al., 2005). Finally, stereotypies, perseveration, and restricted interests can be investigated in mice using exploratory choices and reversal tasks (Crawley, 2004; Presti et al., 2004).

Thorough phenotypic assessment of general health, sensory abilities, and motor functions will be essential to rule out potential artifacts caused by physical disabilities (Crawley, 2000). For exam-

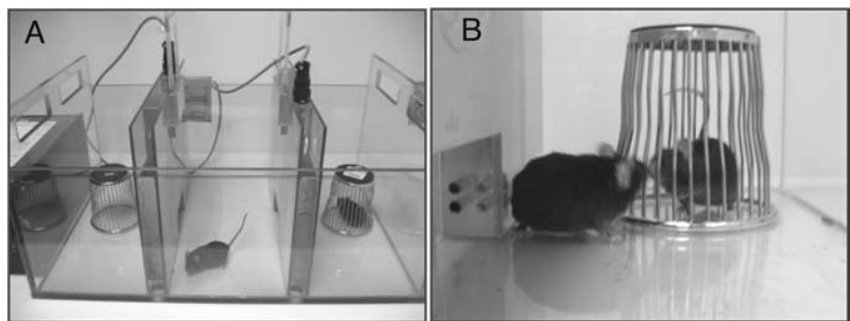

Figure 3. Methods for phenotyping animal social behavior. $A$, The subject mouse is placed in the center chamber and has a choice between spending time exploring a novel object, the wire pencil cup in the left compartment, or spending time with a novel mouse, in the right compartment. Photocells across the openings detect the movements between compartments. Software scores the time in each compartment and number of compartment entries. Normal mice of most inbred strains spend more time in the compartment containing the stranger mouse. $\boldsymbol{B}$, Social interaction between the subject mouse and the unfamiliar conspecific is scored by an observer with a stopwatch. Containing the stranger mouse in the wire cup ensures that all social approach is initiated by the subject mouse and is investigatory only, with no opportunity for sexual or aggressive interactions (Crawley, 2000, 2004).

ple, a mutation that affects olfaction could be mistakenly interpreted as impairing social interaction. A true social deficit, for example, in a mouse with a targeted gene mutation or in an inbred strain of mice, would be a useful means to evaluate potential treatments for core symptoms of ASD.

\section{Social behavior and the role of neuropeptides}

Animal models of normal social behavior may provide insights regarding the social phenotypes in individuals with ASD. Two sets of studies in rodents nicely illustrate this point. The first capitalizes on the strikingly different social behavior of prairie voles and montane voles. The monogamous prairie vole is highly social, craves social contact, and forms enduring social bonds with its mate (Carter et al., 1995; Young and Wang, 2004). In contrast, the promiscuous montane vole is socially aloof, prefers to spend time alone, and does not form social bonds. The neuropeptides oxytocin and vasopressin play central roles in regulating this behavior (Young and Wang, 2004). Comparative neuroanatomical studies suggest that the behavior is a result of differences in the brain expression patterns of these peptide receptors. Specifically, oxytocin and vasopressin receptors are highly expressed in the mesolimbic reward structures, nucleus accumbens, and ventral pallidum in prairie voles but not in montane voles. Genetic analysis of the vasopressin receptor gene in the prairie vole reveals that a polymorphic repetitive element likely determines its expression pattern (Young et al., 1999) such that individual differences in the length of the unstable element are responsible for individual differences in social behavior (Hammock and Young, 2005). These animal studies triggered the examination of the human vasopressin receptor gene (avpr1a) that also contains polymorphic repetitive elements. Two independent studies with relatively small sample size have reported that alleles of this polymorphism are associated with ASD (Kim et al., 2001; Wassink et al., 2004). Although this polymorphism is not a major contributor to ASD, variants may interact with other genetic or environmental factors to contribute to the social behavioral phenotype.

Knock-out mice for oxytocin and vasopressin receptors have confirmed the critical role of these genes in regulating social behavior (Ferguson et al., 2001; Bielsky et al., 2004, 2005). As adults, these knock-outs display social amnesia, indicating a deficit in social stimuli processing. Oxytocin knock-out mice pups do not display normal levels of ultrasonic distress vocalizations when 
separated from their mother (Winslow et al., 2000), and they display increased latencies to approach their mother. These behaviors are consistent with those reported for ASD children. One study has reported that ASD children have decreased plasma oxytocin (Modahl et al., 1998). Insights gained from these animal studies will trigger parallel clinical investigations, as seen with the human avprla gene, and may lead to development of targeted treatment strategies such as the use of oxytocin as a therapy for the social deficits in ASD (Hollander et al., 2003). These multiple levels of analysis are beginning to define basic neurobiological mechanisms that could underlie ASD. In turn, this may lead to improvements in disease diagnosis, early and effective treatments, and ultimately, prevention.

\section{Future prospects}

What developments in diagnosis, pathogenesis, and treatment may we look forward to in the near future? Given the developmental origins of ASD and the identification of early behavioral and brain growth abnormalities, we may soon have sensitive tools to diagnose ASD during the first year of life. Early diagnosis may allow more effective teaching and behavioral strategies to maximize developmental progress to enrich the affected child's experience and possibly lessen further mal-development. The structural, metabolic, and functional neuroimaging is characterizing the disordered ASD brain at several levels. Overall, the postnatal brain growth trajectory is increased, with the greatest differences occurring in rostral cerebral cortex, amygdala, and cerebellar hemispheres and reflecting greater changes in white than gray matter. However, the underlying etiology remains to be defined. It is unknown whether or not increased brain size reflects a normal balance of cell types, although functional connectivity and activity relationships among specific brain regions are disturbed. At the cellular level, the question of cell number in ASD should be addressed soon as ongoing stereological studies of forebrain and hindbrain regions reach completion. The increasing precision of fMRI may reveal correlations of network activity with individual symptoms in individual patients, providing a means to assess therapy.

We are also on the verge of genetic discoveries that will focus attention on a number of developmental regulators and processes, neurotransmitter and synaptic components and, potentially, novel genetic mechanisms that contribute to ASD susceptibility in the context of specific environmental factors. Progress in animal models should allow investigators to examine specific ASD components using approaches based on the fundamental neurobiology, endophenotypes, susceptibility genes, and pathogenetic factors. Hopefully, such animal models will allow additional definition of the molecular pathways in human ASD populations. For example, the oxytocin-vasopressin receptor studies have led to new human genetic studies, and the association of EN2 with ASD raises questions about the relationships of genotype to brain morphology, on the one hand, and the range of clinical symptoms, on the other. From a broader perspective, successful communication among investigators across traditional disciplinary boundaries is essential to establish the validity of animal and genetic models of the human disorder. Meanwhile, the clinician faces the challenge of fitting newly defined developmental and molecular mechanisms with clinical subpopulations for additional study. We are in an exciting time for ASD research with the convergence of enhanced societal concern, increased research support, and the emerging realization by neurobiologists that studies of ASD may lead to fundamental insights into the development and function of the brain.

\section{References}

Alarcon M, Yonan AL, Gilliam TC, Cantor RM, Geschwind DH (2005) Quantitative genome scan and Ordered-Subsets Analysis of autism endophenotypes support language QTLs. Mol Psychiatry 10:747-757.

American Psychiatric Association (1994) Diagnostic and statistical manual of mental disorders, Ed 4. Washington, DC: American Psychiatric Association.

Araghi-Niknam M, Fatemi SH (2003) Levels of Bcl-2 and P53 are altered in superior frontal and cerebellar cortices of autistic subjects. Cell Mol Neurobiol 23:945-952.

Arndt TL, Stodgell CJ, Rodier PM (2005) The teratology of autism. Int J Dev Neurosci 23:189-199.

Ashwood P, Van de Water J (2004) Is autism an autoimmune disease? Autoimmun Rev 3:557-562.

Aylward EH, Minshew NJ, Field K, Sparks BF, Singh N (2002) Effects of age on brain volume and head circumference in autism. Neurology 59:175-183.

Baader SL, Sanlioglu S, Berrebi AS, Parker-Thornburg J, Oberdick J (1998) Ectopic overexpression of Engrailed-2 in cerebellar Purkinje cells causes restricted cell loss and retarded external germinal layer development at lobule junctions. J Neurosci 18:1763-1773.

Bailey A, Luthert P, Dean A, Harding B, Janota I, Montgomery M, Rutter M, Lantos P (1998) A clinicopathological study of autism. Brain 121:889-905.

Baron-Cohen S, Ring HA, Wheelwright S, Bullmore ET, Brammer MJ, Simmons A, Williams SCR (1999) Social intelligence in the normal and autistic brain: an fMRI study. Eur J Neurosci 11:1891-1898.

Bartlett CW, Gharani N, Millonig JH, Brzustowicz LM (2005) Three autism candidate genes: a synthesis of human genetic analysis with other disciplines. Int J Dev Neurosci 23:221-234.

Bauman ML (1991) Microscopic neuroanatomic abnormalities in autism. Pediatrics 87:791-795.

Benayed R, Gharani N, Rossman I, Mancuso V, Lazar G, Kamdar S, Bruse SE, Tischfield S, Smith BJ, Zimmerman RA, DiCicco-Bloom E, Brzustowicz LM, Millonig JH (2005) Support for the homeobox transcription factor, ENGRAILED 2, as an autism spectrum disorder (ASD) susceptibility locus. Am J Hum Genet 77:851-868.

Bertone A, Mottron L, Jelenic P, Faubert J (2005) Enhanced and diminished visuo-spatial information processing in autism depends on stimulus complexity. Brain 128:2430-2441.

Bettelheim B (1967) The empty fortress: infantile autism and the birth of the self. Oxford: Free Press of Glencoe.

Bielsky IF, Hu S-B, Szegda KL, Westphal H, Young LJ (2004) Profound impairment in social recognition and reduction in anxiety in vasopressin V1a receptor knockout mice. Neuropsychopharmacology 29:483-493.

Bielsky IF, Hu SB, Ren X, Terwilliger EF, Young LJ (2005) The V1a vasopressin receptor is necessary and sufficient for normal social recognition: a gene replacement study. Neuron 47:503-513.

Blanchard DC, Griebel G, Blanchard RJ (2003) The mouse defense test battery: pharmacological and behavioral assays for anxiety and panic. Eur J Pharmacol 463:97-116.

Blatt GJ, Fitzgerald CM, Guptill JT, Booker AB, Kemper TL, Bauman ML (2001) Density and distribution of hippocampal neurotransmitter receptors in autism: an autoradiographic study. J Autism Dev Disord 31:537-543.

Bolivar VJ, Flaherty L (2003) Assessing autism-like behaviors in inbred strains of mice. Soc Neurosci Abstr 29:318.13.

Boulanger LM, Shatz CJ (2004) Immune signalling in neural development, synaptic plasticity and disease. Nat Rev Neurosci 5:521-531.

Bradford Y, Haines J, Hutcheson H, Gardiner M, Braun T, Sheffield V, Cassavant T, Huang W, Wang K, Vieland V, Folstein S, Santangelo S, Piven J (2001) Incorporating language phenotypes strengthens evidence of linkage to autism. Am J Med Genet [Erratum (2001) 105:805] 105:539547.

Brodkin ES, Hagemann A, Nemetski SM, Silver LM (2004) Social approachavoidance behavior of inbred mouse strains towards DBA/2 mice. Brain Res 1002:151-157.

Brodmann K (1909) Vergleichende Lokalisationslehre der Großhirnrinde in ihren Prinzipien dargestellt auf Grund des Zellenbaues. Leipzig, Germany: J. A. Barth.

Carey RG, Li B, DiCicco-Bloom E (2002) Pituitary adenylate cyclase activating polypeptide anti-mitogenic signaling in cerebral cortical progenitors 
is regulated by $5^{\mathrm{Kip} 2}$-dependent $\mathrm{CDK} 2$ activity. J Neurosci 22:1583-1591.

Carper R, Courchesne E (2005) Localized enlargement of the frontal lobe in autism. Biol Psychiatry 57:126-133.

Carper RA, Moses P, Tigue ZD, Courchesne E (2002) Cerebral lobes in autism: early hyperplasia and abnormal age effects. NeuroImage 16:1038-1051.

Carper RA, Wideman GM, Courchesne E (2006) Structural neuromaging. In: Understanding autism, Chap 16 (Moldin S, ed), pp 349-377. Boca Raton, FL: CRC.

Carter CS, DeVries AC, Getz LL (1995) Physiological substrates of mammalian monogamy: the prairie vole model. Neurosci Biobehav Rev 19:303-314

Casanova MF, Buxhoeveden DP, Switala AE, Roy E (2002a) Minicolumnar pathology in autism. Neurology 58:428-432.

Casanova MF, Buxhoeveden DP, Switala AE, Roy E (2002b) Neuronal density and architecture (gray level index) in the brains of autistic patients. J Child Neurol 17:515-521.

Castelli F, Frith C, Happe F, Frith U (2002) Autism, Asperger's syndrome and brain mechanisms for the attribution of mental states to animated shapes. Brain 125:1839-1849.

Chakrabarti S, Fombonne E (2001) Pervasive developmental disorders in preschool children. J Am Med Assoc 285:3093-3099.

Cheng T, Black IB, DiCicco-Bloom E (2002) Hippocampal granule neuron production and population size are regulated by levels of bFGF. Eur J Neurosci 15:3-12.

Cheng Y, Tao Y, Black IB, DiCicco-Bloom E (2001) A single peripheral injection of basic fibroblast growth factor (bFGF) stimulates granule cell production and increases cerebellar growth in new born rats. J Neurobiol 46:220-229.

Cody H, Pelphrey K, Piven J (2002) Structural and functional magnetic resonance imaging of autism. Int J Dev Neurosci 20:421-438.

Coleman PD, Romano J, Lapham L, Simon W (1985) Cell counts in cerebral cortex of an autistic patient. J Autism Dev Disord 15:245-255.

Connolly AM, Chez M, Streif EM, Keeling RM, Golumbek PT, Kwon JM, Riviello JJ, Robinson RG, Neuman RJ, Deuel RM (2006) Brain-derived neurotrophic factor and autoantibodies to neural antigens in sera of children with autistic spectrum disorders, Landau-Kleffner syndrome, and epilepsy. Biol Psychiatry 59:354-363.

Courchesne E (2004) Brain development in autism: early overgrowth followed by premature arrest of growth. Ment Retard Dev Disabil Res Rev 10:106-111.

Courchesne E, Pierce K (2005a) Brain overgrowth in autism during a critical time in development: implications for frontal pyramidal neuron and interneuron development and connectivity. Int J Dev Neurosci 23:153-170.

Courchesne E, Pierce K (2005b) Why the frontal cortex in autism might be talking only to itself: local over-connectivity but long-distance disconnection. Curr Opin Neurobiol 15:225-230.

Courchesne E, Karns CM, Davis HR, Ziccardi R, Carper RA, Tigue ZD, Chisum HJ, Moses P, Pierce K, Lord C, Lincoln AJ, Pizzo S, Schreibman L, Haas RH, Akshoomoff NA, Courchesne RY (2001) Unusual brain growth patterns in early life in patients with autistic disorder: an MRI study. Neurology 57:245-254.

Courchesne E, Redcay E, Kennedy DP (2004) The autistic brain: birth through adulthood. Curr Opin Neurol 56:269-278.

Crawley JN (2000) What's wrong with my mouse? Behavioral phenotyping of transgenic and knockout mice. New York: Wiley.

Crawley JN (2004) Designing mouse behavioral tasks relevant to autisticlike behaviors. Ment Retard Dev Disabil Res Rev 10:248-258.

Critchley H, Daly E, Phillips M, Brammer M, Bullmore E, Williams S, Van Amelsvoort T, Robertson D, David A, Murphy D (2000) Explicit and implicit neural mechanisms for processing of social information from facial expressions: a functional magnetic resonance imaging study. Hum Brain Mapp 9:93-105.

Dalton KM, Nacewicz BM, Johnstone T, Schaefer HS, Gernsbacher MA, Goldsmith HH, Alexander AL, Davidson RJ (2005) Gaze fixation and the neural circuitry of face processing in autism. Nat Neurosci 8:519-526.

Dapretto M, Davies MS, Pfeifer JH, Scott AA, Sigman M, Bookheimer SY, Iacoboni M (2006) Understanding emotions in others: mirror neuron dysfunction in children with autism spectrum disorders. Nat Neurosci 9:28-30.

Devlin B, Cook Jr EH, Coon H, Dawson G, Grigorenko EL, McMahon W,
Minshew N, Pauls D, Smith M, Spence MA, Rodier PM, Stodgell C, Schellenberg GD; CPEA Genetics Network (2005) Autism and the serotonin transporter: the long and short of it. Mol Psychiatry 10:1110-1116.

DiCicco-Bloom E (2005) Preface. Int J Dev Neurosci 23:117-124.

Fatemi SH (2001) Reelin mutations in mouse and man: from reeler mouse to schizophrenia, mood disorders, autism and lissencephaly. Mol Psychiatry 6:129-133.

Fatemi SH, Halt AR (2001) Altered levels of Bcl2 and p53 proteins in parietal cortex reflect deranged apoptotic regulation in autism. Synapse 42:281-284.

Fatemi SH, Halt AR, Realmuto G, Earle J, Kist DA, Thuras P, Merz A (2002) Purkinje cell size is reduced in cerebellum of patients with autism. Cell Mol Neurobiol 22:171-175.

Fehlow P, Bernstein K, Tennstedt A, Walther F (1993) Autismus infantum und exzessive Aerophagie mit symptomatischem Megakolon und Ileus bei einem Fall von Ehlers-Danlos-Syndrom [Early infantile autism and excessive aerophagy with symptomatic megacolon and ileus in a case of Ehlers-Danlos syndrome]. Padiatr Grenzgeb 31:259-267.

Ferguson JN, Aldag JM, Insel TR, Young LJ (2001) Oxytocin in the medial amygdala is essential for social recognition in the mouse. J Neurosci 21:8278-8285.

Fombonne E (2003a) The prevalence of autism. J Am Med Assoc 289:87-89.

Fombonne E (2003b) Epidemiological surveys of autism and other pervasive developmental disorders: an update. J Autism Dev Disord 33:365-382.

Friedman SD, Shaw DW, Artru AA, Richards TL, Gardner J, Dawson G, Posse S, Dager SR (2003) Regional brain chemical alterations in young children with autism spectrum disorder. Neurology 60:100-107.

Gharani N, Benayed R, Mancuso V, Brzustowicz LM, Millonig JH (2004) Association of the homeobox transcription factor, ENGRAILED 2, 3, with autism spectrum disorder. Mol Psychiatry 9:474-484.

Gustafsson L (1997) Excessive lateral feedback synaptic inhibition may cause autistic characteristics. J Autism Dev Disord 27:219-220.

Grill-Spector K, Knouf N, Kanwisher N (2004) The fusiform face area subserves face perception, not generic within-category identification. Nat Neurosci 7:555-562.

Guerin P, Lyon G, Barthelemy C, Sostak E, Chevrollier V, Garreau B, Lelord G (1996) Neuropathological study of a case of autistic syndrome with severe mental retardation. Dev Med Child Neurol 38:203-211.

Hammock EAD, Young LJ (2005) Microsatellite instability generates diversity in brain and sociobehavioral traits. Science 308:1630-1634.

Hashimoto T, Tayama M, Murakawa K, Yoshimoto T, Miyazaki M, Harada M, Kuroda Y (1995) Development of the brainstem and cerebellum in autistic patients. J Autism Dev Disord 25:1-18.

Hazlett HC, Poe M, Gerig G, Smith RG, Provenzale J, Ross A, Gilmore J, Piven J (2005) Magnetic resonance imaging and head circumference study of brain size in autism: birth through age 2 years. Arch Gen Psychiatry 62:1366-1376.

Herbert MR, Ziegler DA, Makris N, Filipek PA, Kemper TL, Normandin JJ, Sanders HA, Kennedy DN, Caviness Jr VS (2004) Localization of white matter volume increase in autism and developmental language disorder. Ann Neurol 55:530-540.

Hof PR, Knabe R, Bovier P, Bouras C (1991) Neuropathological observations in a case of autism presenting with self-injury behavior. Acta Neuropathol 82:321-326.

Hollander E, Novotny S, Hanratty M, Yaffe R, DeCaria CM, Aronowitz BR, Mosovich S (2003) Oxytocin infusion reduces repetitive behaviors in adults with autistic and Asperger's disorders. Neuropsychopharmacology 28:193-198.

Insel TR, Young LJ (2001) The neurobiology of attachment. Nat Rev Neurosci 2:129-136.

Just MA, Cherkassky VL, Keller TA, Minshew NJ (2004) Cortical activation and synchronization during sentences comprehension in highfunctioning autism: evidence of underconnectivity. Brain 127:1811-1821.

Kanner L (1943) Autistic disturbances of affective contact. Nerv Child 2:217-250.

Kaufmann WE, Cooper KL, Mostofsky SH, Capone GT, Kates WR, Newschaffer CJ, Bukelis I, Stump MH, Jann AE, Lanham DC (2003) Specificity of cerebellar vermian abnormalities in autism: a quantitative magnetic resonance imaging study. J Child Neurol 18:463-470. 
Kemper TL, Bauman ML (1993) The contribution of neuropathologic studies to the understanding of autism. Neurol Clin 11:175-187.

Kim S, Young LJ, Gonen D, Veenstra-VanderWeele J, Courchesne R, Courchesne E, Lord C, Leventhal BL, Cook EH, Insel TR (2001) Transmission disequilibrium testing of arginine vasopressin receptor $1 \mathrm{~A}$ (AVPR1A) polymorphisms in autism. Mol Psychiatry 7:503-507.

Klin A, Jones W, Schultz RT, Volkmar F, Cohen DJ (2002) Visual fixation patterns during viewing of naturalistic social situations as predictors of social competence in individuals with autism. Arch Gen Psychiatry 59:809-816.

Landa R, Garrett-Mayer E (2006) Development in infants with autism spectrum disorders: a prospective study. J Child Psychol Psychiatry 47:629-638.

Lander E, Kruglyak L (1995) Genetic dissection of complex traits: guidelines for interpreting and reporting linkage results. Nat Genet 11:241-247.

Langdell T (1978) Recognition of faces: an approach to the study of autism. J Child Psychol Psychiatry 19:255-268.

Lee M, Martin-Ruiz C, Graham A, Court J, Jaros E, Perry R, Iversen P, Bauman M, Perry E (2002) Nicotinic receptor abnormalities in the cerebellar cortex in autism. Brain 125:1483-1495.

Li B, DiCicco-Bloom E (2004) bFGF exhibits dual and rapid regulation of cyclin D1 and $\mathrm{p} 27^{\mathrm{KIP} 1}$ to stimulate proliferation of rat cerebral cortical precursors. Dev Neurosci 26:197-207.

Lim MM, Bielsky IF, Young LJ (2005) Neuropeptides and the social brain: potential rodent models of autism. Int J Dev Neurosci 23:235-243.

London EA (2000) The environment as an etiologic factor in autism: a new direction for research. Environ Health Perspect 108 [Suppl 3]:401-404.

Lord C, Bailey A (2002) Autism spectrum disorders. In: Child and adolescent psychiatry, Ed 4 (Rutter M, Taylor E, eds). Oxford: Blackwell Publications.

Lord C, Leventhal BL, Cook Jr EH (2001) Quantifying the phenotype in autism spectrum disorders. Am J Med Genet 105:36-38.

Luyster R, Richler J, Risi S, Hsu WL, Dawson G, Bernier R, Dunn M, Hepburn S, Hyman SL, McMahon WM, Goudie-Nice J, Minshew N, Rogers S, Sigman M, Spence MA, Goldberg WA, Tager-Flusberg H, Volkmar FR, Lord C (2005) Early regression in social communication in autistic spectrum disorders: a CPEA study. Dev Neuropsychol 27:311-336.

Martin-Ruiz CM, Lee M, Perry RH, Baumann M, Court JA, Perry EK (2004) Molecular analysis of nicotinic receptor expression in autism. Brain Res Mol Brain Res 123:81-90.

Millen KJ, Wurst W, Herrup K, Joyner AL (1994) Abnormal embryonic cerebellar development and patterning of postnatal foliation in two mouse Engrailed-2 mutants. Development 120:695-706.

Miller MT, Strömland K, Ventura L, Johansson M, Bandim JM, Gillberg C (2005) Autism associated with conditions characterized by developmental errors in early embryogenesis: a mini-review. Int J Dev Neurosci 23:201-219.

Modahl C, Green LA, Fein D, Morris M, Waterhouse L, Feinstein C, Levin H (1998) Plasma oxytocin levels in autistic children. Biol Psychiatry 43:270-277.

Moy SS, Nadler JJ, Perez A, Barbaro RP, Johns JM, Magnuson TR, Piven J, Crawley JN (2004) Socability and preference for social novelty in five inbred strains: an approach to assess autistic-like behaviors in mice. Genes Brain Behav 3:287-302.

Mukaetova-Ladinska EB, Arnold H, Jaros E, Perry R, Perry E (2004) Depletion of MAP2 expression and laminar cytoarchitectonic changes in dorsolateral prefrontal cortex in adult autistic individuals. Neuropathol Appl Neurobiol 30:615-623.

Nadler JJ, Moy SS, Dold G, Trang D, Simmons N, Perez A, Young NB, Barbaro RP, Piven J, Magnuson TR, Crawley JN (2004) Automated apparatus for rapid quantitation of autism-like social deficits in mice. Genes Brain Behav 3:303-314.

Nicot A, Lelièvre V, Tam J, Waschek JA, DiCicco-Bloom E (2002) Pituitary adenylate cyclase-activating polypeptide (PACAP) and sonic hedgehog (Shh) interact to control cerebellar granule precursor cell proliferation. J Neurosci 22:9244-9254.

Palmen SJ, van Engeland H (2004) Review on structural neuroimaging findings in autism. J Neural Transm 111:903-929.

Palmen SJ, van Engeland H, Hof PR, Schmitz C (2004) Neuropathologic findings in autism. Brain 127:2572-2583.

Pelphrey KA, Morris JP, McCarthy G (2005) Neural basis of eye gaze processing deficits in autism. Brain 128:1038-1048.
Petrulis A, Alvarez P, Eichenbaum H (2005) Neural correlates of social odor recognition and the representation of individual distinctive social odors within entorhinal cortex and ventral subiculum. Neuroscience 130:259-274.

Pierce K, Müller RA, Ambrose J, Allen G, Courchesne E (2001) Face processing occurs outside the fusiform "face area" in autism: evidence from functional MRI. Brain 124:2059-2073.

Polleux F, Lauder JM (2004) Toward a developmental neurobiology of autism. Ment Retard Dev Disabil Res Rev 10:303-317.

Presti MF, Watson CJ, Kennedy RT, Yang M, Lewis MH (2004) Behaviorrelated alterations of striatal neurochemistry in a mouse model of stereotyped movement disorder. Pharmacol Biochem Behav 77:501-507.

Raymond GV, Bauman ML, Kemper TL (1996) Hippocampus in autism: a Golgi analysis. Acta Neuropathol 91:117-119.

Redcay E, Courchesne E (2005) When is the brain enlarged in autism? A meta-analysis of all brain size reports. Biol Psychiatry 58:1-9.

Risch N, Spiker D, Lotspeich L, Nouri N, Hinds D, Hallmayer J, Kalaydjieva L, McCague P, Dimiceli S, Pitts T, Nguyen L, Yang J, Harper C, Thorpe D, Vermeer S, Young H, Hebert J, Lin A, Ferguson J, Chiotti C, et al. (1999) A genomic screen of autism: evidence for a multilocus etiology. Am J Hum Genet 65:493-507.

Ritvo ER, Freeman BJ, Scheibel AB (1986) Lower Purkinje cell counts in the cerebella of four autistic subjects: initial findings of the UCLA-NSAC autopsy research report. Am J Psychiatry 143:862-866.

Rodier PM, Ingram JL, Tisdale B, Nelson S, Romano J (1996) Embryological origin for autism: developmental anomalies of the cranial nerve motor nuclei. J Comp Neurol 370:247-261.

Rossman IT, Kamdar S, Millonig J, DiCicco-Bloom E (2005) Extracellular growth factors interact with Engrailed 2 (EN2) an autism-associated gene, to control cerebellar development. Soc Neurosci Abstr 31:596.2.

Schmitz C, van Kooten IA, Hof PR, van Engeland H, Patterson PH, Steinbusch HW (2005) Autism: neuropathology, alterations of the GABAergic system, and animal models. Int Rev Neurobiol 71:1-26.

Schultz RT (2005) Developmental deficits in social perception in autism: the role of the amygdala and fusiform face area. Int J Dev Neurosci 23:125-141.

Schultz RT, Robins DL (2005) Functional neuroimaging studies of autism spectrum disorders. In Handbook of autism and pervasive developmental disorders, Ed 3 (Volkmar F, Klin A, Paul R, eds), pp 515-533. New York: Wiley.

Schultz RT, Gauthier I, Klin A, Fulbright RK, Anderson AW, Volkmar F, Skudlarski P, Lacadie C, Cohen DJ, Gore JC (2000) Abnormal ventral temporal cortical activity during face discrimination among individuals with autism and Asperger syndrome. Arch Gen Psychiatry 57:331-340.

Schultz RT, Win L, Jackowski A, Klin A, Staib L, Papademetris X, Babitz T, Carter E, Klaiman C, Feiler A, Volkmar F (2005a) Brain morphology in autism spectrum disorders: an MRI study. Paper presented at annual International Meeting for Autism Research, Boston, MA, May.

Schultz RT, Hunyadi E, Conner C, Pasley B (2005b) fMRI study of facial expression perception in autism: the amygdala, fusiform face area and their functional connectivity. Paper presented at the annual meeting of the Organization for Human Brain Mapping, Toronto, Ontario, Canada, June.

Schumann CM, Hamstra J, Goodlin-Jones BL, Lotspeich LJ, Kwon H, Buonocore $\mathrm{MH}$, et al (2004) The amygdala is enlarged in children but not adolescents with autism; the hippocampus is enlarged at all ages. J Neurosci 24:6392-6401.

Shi L, Tu N, Patterson PH (2005) Maternal influenza infection is likely to alter fetal brain development indirectly: the virus is not detected in the fetus. Int J Dev Neurosci 23:299-305.

Sparks BF, Friedman SD, Shaw DW, Aylward EH, Echelard D, Artru AA, Maravilla KR, Giedd JN, Munson J, Dawson G, Dager SR (2002) Brain structural abnormalities in young children with autism spectrum disorder. Neurology 59:184-192.

Strömland K, Nordin V, Miller M, Akerstrom B, Gillberg C (1994) Autism in thalidomide embryopathy: a population study. Dev Med Child Neurol 36:351-356.

Suh J, Lu N, Nicot A, Tatsuno I, DiCicco-Bloom E (2001) PACAP is an anti-mitogenic signal in developing cerebral cortex. Nat Neurosci 4:123-124.

Szatmari P (1999) Heterogeneity and the genetics of autism. J Psychiatry Neurosci 24:159-165. 
Szatmari P, Jones MB, Zwaigenbaum L, Maclean JE (1998) Genetics of autism: overview and new directions. J Autism Dev Disord 28:351-368.

Teramitsu I, Kudo LC, London SE, Geschwind DH, White SA (2004) Parallel FoxP1 and FoxP2 expression in songbird and human brain predicts functional interaction. J Neurosci 24:3152-3163.

Trottier G, Srivastava L, Walker CD (1999) Etiology of infantile autism: a review of recent advances in genetic and neurobiological research. J Psychiatry Neurosci 24:103-115.

Vaccarino FM, Schwartz ML, Raballo R, Nilsen J, Rhee J, Zhou M, Doetschman T, Coffin JD, Wyland JJ, Hung YT (1999) Changes in cerebral cortex size are governed by fibroblast growth factor during embryogenesis. Nat Neurosci 2:848.

Vargas DL, Nascimbene C, Krishnan C, Zimmerman AW, Pardo CA (2005) Neuroglial activation and neuroinflammation in the brain of patients with autism. Ann Neurol 57:67-81.

Vogt C, Vogt O (1919) Allgemeinere Ergebnisse unserer Hirnforschung. J Psychol Neurol 25:292-398.

Vorstman JA, Staal WG, van Daalen E, van Engeland H, Hochstenbach PF, Franke L (2006) Identification of novel autism candidate regions through analysis of reported cytogenetic abnormalities associated with autism. Mol Psychiatry 11:18-28.

Wassink TH, Brzustowicz LM, Bartlett CW, Szatmari P (2004) The search for autism disease genes. Ment Retard Dev Disabil Res Rev 10:272-283.

Wechsler-Reya RJ, Scott MP (1999) Control of neuronal precursor proliferation in the cerebellum by Sonic Hedgehog. Neuron 22:103-114.

Williams RS, Hauser SL, Purpura DP, DeLong GR, Swisher CN (1980) Autism and mental retardation: neuropathologic studies performed in four retarded persons with autistic behavior. Arch Neurol 37:749-753.

Winslow JT (2005) Neuropeptides and non-human primate social deficits associated with pathogenic rearing experience. Int J Dev Neurosci 23:245-251.
Winslow JT, Insel TR (2002) The social deficits of the oxytocin knockout mouse. Neuropeptides 36:221-229.

Winslow JT, Hearn EF, Ferguson J, Young LJ, Matzuk MM, Insel TR (2000) Infant vocalization, adult aggression, and fear behavior of an oxytocin null mutant mouse. Horm Behav 37:145-155.

Wrenn CC, Harris AP, Saavedra MC, Crawley JN (2003) Social transmission of food preference in mice: methodology and application to galaninoverexpressing transgenic mice. Behav Neurosci 117:21-31.

Xu J, Zwaigenbaum L, Szatmari P, Scherer S (2004) Molecular cytogenetics of autism: current status and future directions. Curr Genomics 5:347-364.

Yirmiya N, Gamliel I, Pilowsky T, Feldman R, Baron-Cohen S, Sigman M (2006) The development of siblings of children with autism at 4 and 14 months: social engagement, communication and cognition. J Child Psychol Psychiatry 47:511-523.

Young LJ, Wang Z (2004) The neurobiology of pair bonding. Nat Neurosci 7:1048-1054

Young LJ, Nilsen R, Waymire KG, MacGregor GR, Insel TR (1999) Increased affiliative response to vasopressin in mice expressing the vasopressin receptor from a monogamous vole. Nature 400:766-768.

Young LJ, Pitkow LJ, Ferguson JN (2002) Neuropeptides and social behavior: animal models relevant to autism. Mol Psychiatry 7 [Suppl 2]:S38-S39.

Zwaigenbaum L, Bryson S, Roberts W, Brian J, Szatmari P (2005) Behavioral markers of autism in the first year of life. Int J Dev Neurosci 23:143-152.

Zwaigenbaum L, Thurm A, Stone W, Baranek G, Bryson SE, Iverson J, Kau A, Klin A, Lord C, Landa R, Rogers S, Sigman M (2006) Studying the emergence of autism spectrum disorders in high risk infants: methodological and practical issues. J Autism Dev Disord, in press. 